Pesq. Vet. Bras. 20(2):80-84, abr./jun. 2000

\title{
Sorovares de Salmonella em carne de equî́deos abatidos no nordeste do Brasil ${ }^{1}$
}

\author{
Ernesto Hofer ${ }^{2}$, Marita Rodrigues Navas Zamora ${ }^{3}$, Antonio Emery Lopes ${ }^{3}$, Ana Maria \\ Camelo de Moura ${ }^{3}$, Heliani Lins de Araújo ${ }^{3}$, Joana D’Arc Didier Leite ${ }^{3}$, Maria \\ Domênica Didier Leite ${ }^{3}$ e Sebastião Januário da Silva Filho ${ }^{2,4}$
}

\begin{abstract}
Hofer E., Zamora M.R.N., Lopes A.E., Moura A.M.C., Araújo H.L., Leite M.D.D. \& Silva Filho S.J. 2000. [Salmonella serovars in meat of horses slaughtered in northeastern Brazil.] Sorovares de Salmonella em carne de equí́deos abatidos no nordeste do Brasil. Pesquisa Veterinária Brasileira 20(2):80-84. Depto Bacteriologia, Instituto Oswaldo Cruz/FIOCRUZ, Rio de Janeiro, RJ 21045-900, Brazil.

In the sixties and seventies there was an extraordinary increase in export of horse meat products to Europe and Japan. This favored an increase in risk of Salmonella outspread through those products to human and animal consumer populations. Thus, from an exporting company dealing with horse meat located in northeastern Brazil (state of Pernambuco), 19,238 fragments of more external muscles, Salmonella was isolated from 666 samples colleted from 433 animals (horses and donkeys). The serotyping of 745 isolates showed 98 serovars pertaining to 14 serogroups, predominantly classified into subspecies I (98.9\%). S. Anatum, S. Carrau, S. Saintpaul, $S$. Agona, and $S$. Typhimurium were the most frequent serovars isolated. Preliminary data indicate that the primary causes for the presence of Salmonella in the meats probably was contact with feces from slaughtered animals, as well as possible contamination of environments, in view of the absence of human carriers researched in part of the personnel.
\end{abstract}

INDEX TERMS: Horses, horse meat, Salmonella, serogroups, serovars.

SINOPSE - Nas décadas de 60 e 70, houve um extraordinário incremento da exportação de produtos cárneos de equí́deos dos países da América do Sul para a Europa e Japão. Este acontecimento favoreceu o aumento de risco da veiculação de Salmonella através desses produtos, para as populações humana e animal, consumidoras. Assim, num estabelecimento industrial e exportador de carne de equí́deos localizado no nordeste do Brasil (Pernambuco), foram analisados bacteriologicamente, 19.238 fragmentos de músculos mais externos, que revelaram 666 exames positivos referentes a 433 animais (eqüinos e asininos) e resultando no isolamento de 745 cepas de Salmonella. Na amostragem foram caracterizados do ponto de vista antigênico 98 sorovares, predominantemente classificados na subespécie I $(98,9 \%)$ e tendo como

\footnotetext{
${ }^{1}$ Aceito para publicação em 16 de fevereiro de 2000.

${ }^{2}$ Depto Bacteriologia, Instituto Oswaldo Cruz/FIOCRUZ, Av. Brasil 4365, Manguinhos, Rio de Janeiro, RJ 21045-900.

${ }^{3}$ Grupo Executivo de Inspeção de Produtos de Origem Animal (GEIPOA/PE), Ministério da Agricultura, Recife, Pernambuco (extinto).

${ }^{4}$ In memoriam, falecido em 10.1.89.
}

os mais freqüentes S. Anatum, S. Carrau, S. Saintpaul, S. Agona e $S$. Typhimurium. Pelas análises efetuadas admite-se que as causas primordiais da presença de Salmonella nas carnes, provavelmente decorreu do contato com os excretas dos animais abatidos, bem como pela possível contaminação ambiental resultante, tendo em vista a ausência de portadores humanos, pesquisados numa parcela do pessoal.

TERMOS DE INDEXAÇÃO: Equídeos, produtos cárneos, Salmonella, sorogrupos, sorovares.

\section{INTRODUÇÃO}

As investigações sobre a ocorrência de Salmonella em equí́deos, particularmente em seus produtos utilizados para o consumo humano e animal, são muito exíguas na literatura, apesar dos relatos feitos durante a década de 60 na Inglaterra por Hobbs (1965) e na Holanda por Schothorst \& Kampelmacher (1967), que evidenciaram uma elevada taxa de contaminação nas carnes de eqüínos de origem sulamericana. É interessante ressaltar que o mesmo problema foi descrito por Anderson \& Lee (1976) nos animais abatidos nos Estados Unidos da América. 
Na América do Sul, também são muito discretas as citações, concentrando-se nas observações efetuadas por Pérez et al.(1950) no Chile; Monteverde et al. (1969); Quevedo et al. (1973) na Argentina e Giorgi (1973) no Brasil, que pesquisaram a Salmonella em linfonodos mesentéricos e nas fezes de eqüinos aparentemente normais. Em complemento à referência nacional, assinalam-se as investigações de Paula et al. (1975) e Zamora et al. (1978) voltadas na pesquisa desta enterobactéria em carnes congeladas ou não de equídeos, próprias para exportação.

Considerando a carência de dados neste campo em todo o mundo, objetivou-se no presente trabalho, caracterizar a incidência de sorovares de Salmonella em produtos cárneos de equí́deos abatidos no Brasil e exportados para diferentes partes do mundo e por conseguinte, ofertar subsídios para a Saúde Pública.

\section{MATERIAL E MÉTODOS}

Amostragem

No período de 1980 a 1982, o Laboratório de Inspeção Federal, Ministério da Agricultura, instalado especificamente num frigorífico industrial, localizado no município de Belo Jardim, Pernambuco, analisou bacteriologicamente 19.238 amostras de carnes de equíideos aparentemente normais e abatidos para consumo humano e animal fora do país. Os animais constituídos de 61\% de Equus caballus e 39\% de E. asinus, provieram de criações do nordeste brasileiro (Bahia, Alagoas, Pernambuco, Paraíba, Rio Grande do Norte, Ceará, Piauí e Maranhão), predominando os animais adquiridos em Pernambuco e na Paraíba.

\section{Isolamento e identificação presuntiva}

O processo bacteriológico aplicado pelo Laboratório de Inspeção Federal, foi de natureza tipicamente qualitativo, consistindo no préenriquecimento de vários fragmentos de músculos, totalizando aproximadamente $25 \mathrm{~g}$, retirados das porções mais externas das carcaças com instrumental esterilizado, em $225 \mathrm{ml}$ de caldo lactosado, e incubado a $37^{\circ} \mathrm{C}$ por 18 horas. Dos crescimentos transferiram-se inóculos de $10 \mathrm{ml}$ para $100 \mathrm{ml}$ de caldo Tetrationato de Kauffmann e caldo Selenito-Cistina, respectivamente, incubando-os durante 24 horas a $37^{\circ} \mathrm{C}$. Em seqüência, efetuou-se o repique destes cultivos para os meios seletivos-indicadores, representados por Agar EMB, Agar SS e Agar Entérico Hektoen (todos Difco), sendo incubados a $37^{\circ} \mathrm{C}$ por 18 horas.

A caracterização bioquímica presuntiva das 3 a 5 colônias lactose negativas isoladas dos meios seletivos, se baseou nos comportamentos observados após 18 horas a $37^{\circ} \mathrm{C}$ em Agar Tríplice AçúcarFerro (TSI) e Agar Lisina-Ferro (LIA).

\section{Caracterizações fenotípicas específicas}

As culturas selecionadas como suspeitas de Salmonella com base nos resultados observados nos meios de triagem foram semeadas em tubos com agar nutriente (Difco) e remetidas para o Laboratório de Enterobactérias do Instituto Oswaldo Cruz, FIOCRUZ, Rio de Janeiro, onde se efetuaram as análises fenotípicas conclusivas, incluindo a caracterização antigênica somática e flagelar, de acordo com as recomendações de Costa \& Hofer (1972), Ewing (1986) e Le Minor \& Popoff (1987).

Na representação dos sorovares de Salmonella, adotou-se a nomenclatura preconizada por. Le Minor \& Popoff (1987).

\section{RESULTADOS}

Nas 19.238 análises realizadas no triênio, os membros do gênero Salmonella foram detectados em 666 espécimes $(3,4 \%)$ colhidos de 433 animais, sendo $260(60,1 \%)$ de equínos e $173(39,9 \%)$ de asininos, predominantemente originários de Pernambuco (194-44,7\%) e Paraíba (129-29,7\%). Salienta-se que dos espécimes positivos, 79 exames revelaram dois tipos distintos de Salmonella e que no cômputo geral, possibilitaram o isolamento de 745 amostras, cuja distribuição em sorogrupos e respectivos sorovares, está assinalada no Quadro 1.

Em relação aos sorovares, salienta-se a caracterização de 98 tipos distintos, predominantemente enquadrados na subespécie I, incluindo as formas rugosas (737-98,9\%), com discreta ocorrência das subespécies II $(2-0,26 \%)$, IIIa $(1-0,13 \%)$ e IIIb $(5-0,67 \%)$, tendo por base os resultados apresentados no Quadro 1.

Finalmente no Quadro 2, foram ordenados os dezessete sorovares mais incidentes no período, mas tomando-se o cuidado de excluir as salmonelas na forma rugosa (12 amostras). È interessante destacar que o nível de ocorrência desses sorotipos nos dados totais, atinge a $72,3 \%$, oscilando de 62 a $73 \%$, de acordo com o ano de isolamento.

\section{DISCUSSÃO}

A salmonelose é uma das zoonoses mais problemáticas para a saúde pública, em decorrência do extraordinário número de fontes de infecção envolvidas, praticamente todos os vertebrados, alguns dos quais, fontes de proteína animal para o homem (Hofer \& Reis 1994).

Nesta condição, situa-se a carne de equíídeos, cujo comércio realizado principalmente por exportadores sulamericanos para a Comunidade Européia (atual União Européia) e Japão, floresceu nas décadas de 60 e 70 . Tal acontecimento suscitou algumas investigações nos países importadores que, surpreendentemente, revelaram um índice de contaminação por Salmonella que atingiu até $34,7 \%$ nos produtos dos equiinos (Hobbs, 1965, Schothorst \& Kampelmacher, 1967), bem mais acentuado que nas carnes de outras espécies animais (Report of a Working Party of the Public Health Laboratory Service, 1964).

É interessante ressaltar que o problema está mais relacionado com a fonte de infecção, pois o fenômeno foi reproduzido em diferentes partes do mundo, inclusive em países desenvolvidos como nos EUA (Anderson \& Lee 1976), onde nos produtos de equí́deos abatidos, para consumos humano e animal, foi evidenciada uma taxa de $26,6 \%$ de Salmonella em 233 espécimes de carnes examinadas. Aliás, esta afinidade entre o enteropatógeno e os eqüinos é evidente nos trabalhos que analisaram através de coproculturas e pesquisa em linfonodos mesentéricos, nos quais a frequiência de portadores hígidos, variou de 15 a 32\% (Pérez et al. 1950, Monteverde et al. 1969, Giorgi 1973, Quevedo et al.1973). Curiosamente, na literatura especializada não se tem qualquer referência sobre abordagem ou esclarecimento tentando explicar essa 
Quadro 1. Distribuição dos sorovares e variantes de Salmonella identificados e classificados nos respectivos sorogrupos

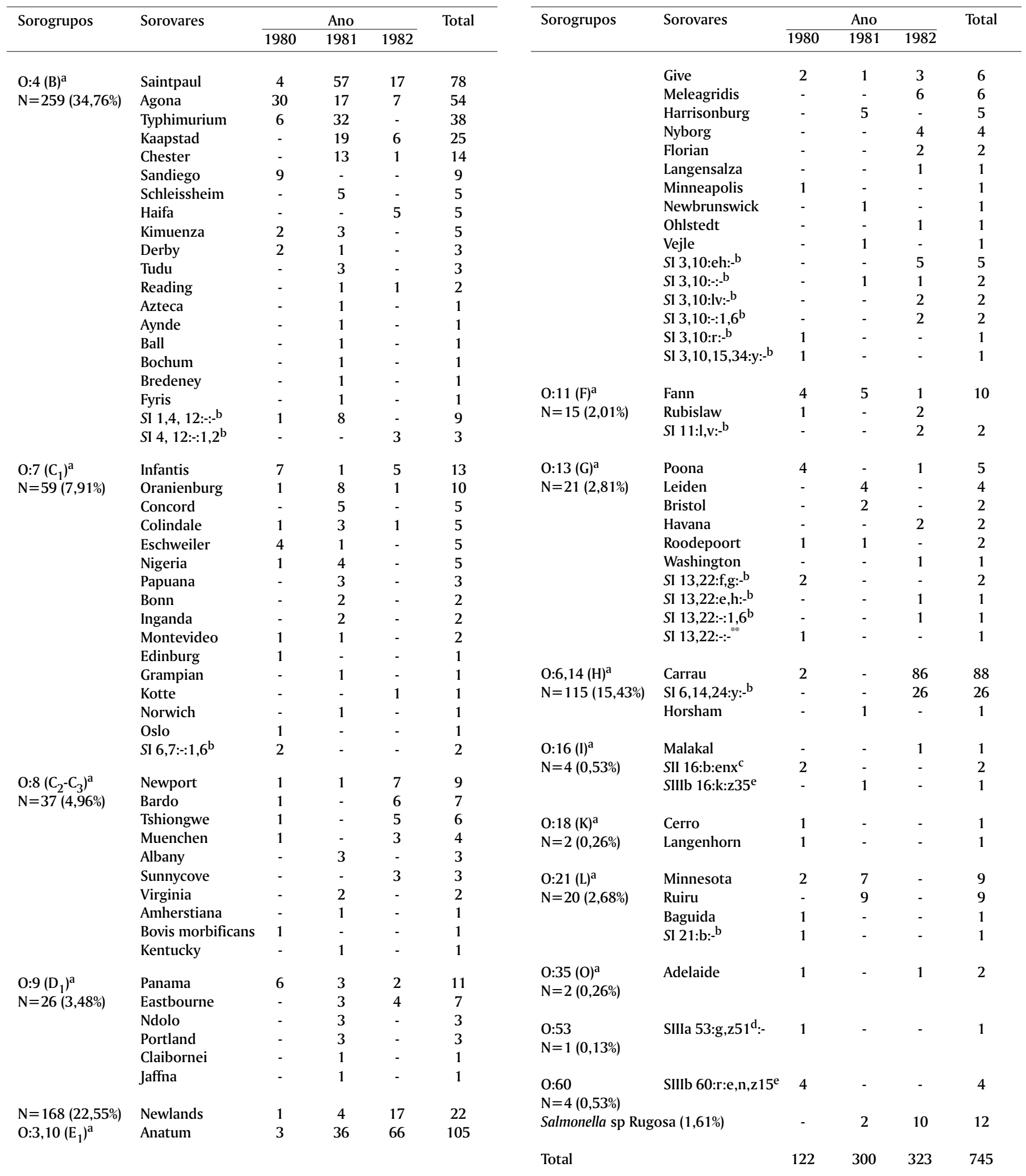

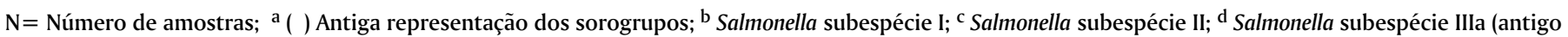
gênero Arizona, monofásica); ${ }^{\mathrm{e}}$ Salmonella subespécie IIIb (antigo gênero Arizona, difásica). 
Tabela 2. Sorovares mais incidentes no triênio 1980-1982 tomando por base as 733 salmonelas isoladas

\begin{tabular}{|c|c|c|c|c|c|}
\hline \multirow[t]{2}{*}{ Sorovares } & \multicolumn{3}{|c|}{ Ano } & \multicolumn{2}{|c|}{ Total } \\
\hline & 1980 & 1981 & 1982 & $\mathrm{~N}^{\mathrm{O}}$ & $\%$ \\
\hline Anatum & 3 & 36 & 66 & 105 & 19,8 \\
\hline Carrau & 2 & - & 86 & 88 & 16,6 \\
\hline Saintpaul & 4 & 57 & 17 & 78 & 14,7 \\
\hline Agona & 30 & 17 & 7 & 54 & 10,1 \\
\hline Typhimurium & 6 & 32 & - & 38 & 7,16 \\
\hline$S_{\mathrm{I}} 6,14: \mathrm{y}:-$ & - & - & 26 & 26 & 4,90 \\
\hline Kaapstad & - & 19 & 6 & 25 & 4,71 \\
\hline Newlands & 1 & 4 & 17 & 22 & 4,15 \\
\hline Chester & - & 13 & 1 & 14 & 2,64 \\
\hline Infantis & 7 & 1 & 5 & 13 & 2,45 \\
\hline Panama & 6 & 3 & 2 & 11 & 2,07 \\
\hline Oranienburg & 1 & 8 & 1 & 10 & 1,88 \\
\hline Fann & 4 & 5 & 1 & 10 & 1,88 \\
\hline Sandiego & 9 & - & - & 9 & 1,65 \\
\hline Newport & 1 & 1 & 7 & 9 & 1,69 \\
\hline Minnesota & 2 & 7 & - & 9 & 1,69 \\
\hline Ruiru & - & 9 & - & 9 & 1,69 \\
\hline Totais & $76(62,2 \%)$ & $212(71,4 \%)$ & $242(77,3 \%)$ & 530 & 72,3 \\
\hline
\end{tabular}

maior permissividade dos equí́deos no desenvolvimento do estado de portador de Salmonella.

Um outro aspecto comum com as investigações efetuadas por Schothrost \& Kampelmacher (1967) e Anderson \& Lee (1976), reside no elevado número de sorovares reconhecidos, como pode ser analisado no Quadro 1. Observa-se como detalhe de importância epidemiológica nestes dados que os sorotipos identificados se concentraram nos sorogrupos $0: 4$, 0:3,10 e 0:6,14, constituídos de 41 tipos antigênicos distintos $(41,8 \%$ do total) e representando 542 amostras $(73,9 \%)$ do total das salmonelas isoladas. Assinala-se que não foi detectado o sorovar Abortus equi, adaptado aos eqüinos e responsável por patologia específica.

A hipótese mais plausível para explicar esta elevada e diversificada frequiência de sorovares nas carcaças e ou carnes, decorra do contato dos produtos com os dejetos dos animais abatidos e, que também favoreceriam à colonização e propagação da bactéria nas dependências do abatedouro. Esta premissa encontra respaldo técnico nas observações efetuadas por Schothorst \& Kampelmacher (1967) e Anderson \& Lee (1976) que demonstraram que a contaminação é preferencialmente reconhecida na superfície da carcaça e de forma excepcional, em massas musculares profundas, que indicaria uma bacteriemia na fase pré-agônica dos animais.

Por outro lado, não se descarta a importância do manipulador nesta etapa, que provavelmente, favoreceria a propagação de contaminantes nas superfícies das carcaças através do manuseio. Esta situação epidemiológica tem o devido amparo nas experiências realizadas por Pether \& Gilbert (1971) que analisaram o grau de eliminação de Salmonella anatum nas pontas dos dedos de voluntários, previamente contaminados. Verificaram que o isolamento da salmonela da polpa digital desses indivíduos, depois de lavadas as mãos com sabão e água corrente por 15 segundos, estava na de- pendência direta da população bacteriana, sendo $100 \%$ positivas com inóculo de $10^{6}$ e $30 \%$ na faixa de $10^{3}$ a $10^{4}$ de $S$. anatum.

Convém associar ao problema retratado e talvez como ponto mais crucial, a influência exercida pelo aumento da infecção, que ocorre nos animais durante seu trajeto e permanência no matadouro até o momento do abate. Aliás, esta situação foi muito bem analisada por Kampelmacher (1976), embora com outras espécies animais e por Anderson \& Lee (1976) nos equí́deos, que evidenciaram uma diferença significativa de animais portadores de Salmonella na fase de préabate em comparação a discreta deteç̧ão da área de criação.

Da mesma forma em nosso meio, em particular no nordeste, admite-se que os animais sofram inúmeras agressões estressantes, resultado dos longos deslocamentos, associando-se à temperatura ambiental elevada, a alimentação precária ou mesmo o jejum prolongado, assim como uma dieta hídrica forçada ou com fornecimento de água em condições sanitárias insatisfatórias.

Quando da chegada ao abatedouro, os animais debilitados, não só pelo deslocamento como também pela idade avançada, pois são os mais freqüentemente vendidos, eram confinados em áreas exíguas para o número recebido, propiciando ainda mais a propagação de Salmonella, tanto nos eqüinos como nos asininos.

Em síntese, os fatores estressantes são capazes comprometer o equilíbrio imunológico nos animais portadores e com isso, favorecer o desencadeamento da enterite clínica ou subclínica nos equíínos, segundo as observações de Smith et al. (1978) e Palmer et al. (1985).

Um aspecto da presente investigação que merece ser destacado ao se confrontar com as outras abordagens é a acentuada compatibilidade dos sorovares identificados, ressalvando-se a ausência do sorotipo Good, um dos mais ocorrentes nas citações de Schothorst \& Kampelmacher (1967), Quevedo et al. (1973)e de Anderson \& Lee (1976). Em contraposição, no presente estudo, salienta-se a elevada frequiência de $S$. Carrau sorovar caracterizado como incomum ou raro em nosso meio (Taunay et al. 1996). É interessante que tanto o sorovar Good como Carrau, não foram apontados na literatura como agentes de processos patológicos em equínos, nas discretas referências sobre esse tema (Palmer et al., 1985).

A faceta mais importante do ponto de vista epidemiológico residiu na incidência daqueles sorovares comuns em processos entéricos humanos, e de outras espécies animais, como $S$. Anatum, S. Saintpaul, S. Agona, $S$. Typhimurium, $S$. Newlands, S. Infantis, $S$. Panama, $S$. Oranienburg e $S$. Newport (Quadro 2). Esses sorovares tem características cosmopolitas, coexistindo nas referências nacionais (Calzada et al. 1984, Leal et al. 1987, Taunay et al. 1996, Hofer et al. 1997), que se detiveram em analisar os sorotipos envolvidos nos processos patológicos humanos e animais. Todavia, a relação entre os produtos cárneos contaminados com as infecções humanas e animais é difícil de ser estabelecida na maioria das vezes, mesmo com recursos técnicos de tipagem mais apropriados, como a lisotipia ou através dos métodos de biologia molecular. Isto decorre pela predominância dos casos esporádicos so- 
bre os raros surtos de salmoneloses humana e animal, o que dificulta, ou mesmo impossibilita estabelecer um elo epidemiológico entre as fontes de infecção e os veículos de transmissão.

Pela maior incidência desses sorovares nos produtos cárneos (Quadro 2), seria viável imputar a influência de portadores humanos entre os operários do frigorífico. Entretanto, as coproculturas seriadas ( 3 amostras fecais colhidas em intervalos de 3 a 4 dias) realizadas num grupo de vinte pessoas, com atividade direta com os animais abatidos e suas carcaças, não possibilitou a deteç̧ão de Salmonella (C. Galindo, comunicação pessoal). Com base nesse resultado, admite-se que a contaminação dos produtos tenha como origem o contato com os excretas dos animais e do ambiente, apesar dos cuidados dispensados nas fases de abate e de manipulação. Por sinal, estas foram as causas apontadas pelos autores europeus e americanos (Hobbs 1965, Schothorst \& Kampelmacher 1967, Anderson \& Lee 1976), embora esta conceituação não tenha sido apoiada por Quevedo et al. (1974).

Agradecimentos.- À colaboração técnica da equipe do antigo Laboratório de Enterobactérias do Departamento de Bacteriologia do Instituto Oswaldo Cruz, ao pessoal de apoio do Frigorífico em Belo Jardim, ao Dr. Carlos Galindo, Caruaru, Pernambuco pela execução das coproculturas e à Sra. Darcília Maria de Andrade, do Laboratório de Zoonoses Bacterianas do IOC, pelo auxílio técnico prestado.

\section{REFERÊNCIAS}

Anderson G.D. \& Lee D.R. 1976. Salmonella in horses: a source of contamination of horsemeat in packing plant under Federal Inspection. Appl. Environ. Microbiol. 31:661-663.

Calzada C.T., Neme S.N., Irino, K., Kano E., Dias A.M.G., Fernandes S.A., Vaz T.M.I. \& Pessôa G.V.A. 1984. Sorotipos de Salmonella identificados no período 1977-1982, no Instituto Adolfo Lutz, São Paulo, Brasil. Revta Inst. Adolfo Lutz, São Paulo, 44:1-18.

Costa G.A. \& Hofer E., 1972. Isolamento e identificação de Enterobactérias. Monografia, Inst. Oswaldo Cruz, Rio de Janeiro.120 p.

Ewing W.H. 1986. Edward and Ewing's Identification of Enterobacteriaceae. 4th ed. Elsevier, New York. 536p.

Giorgi W. 1973. Isolamento de salmonelas de gânglios mesentéricos de equínos abatidos em matadouro. Arqs Inst. Biológico, São Paulo, 40:95-97.

Hobbs B.C. 1965. Contamination of meat supplies. Part I. Salmonella and Staphylococcus. Mon. Bull. Min. \& Public Hlth Lab. Serv. 24:123-144.
Hofer E. \& Reis E.M.F. 1994. Salmonella serovars in food poisoning episodes recorded in Brazil from 1982 to 1991. Revta Inst. Med. Trop., São Paulo, 36:7-9.

Hofer E., Silva Filho S.J. \& Reis E.M.F. 1997. Prevalência de sorovares de Salmonella isolados de aves no Brasil. Pesq. Vet. Bras. 17:55-62.

Kampelmacher E.H. 1963. Salmonellosis in the Netherlands. Ann. Inst. Pasteur, Paris, 104:647-659.

Leal N.C., Sá A.T., Solari C.A., Silva Filho S.J. \& Hofer E. 1987. Sorotipos de Salmonella isolados de procesos entéricos humanos em Recife-Pernambuco durante o triênio 1978-1980. Mem. Inst. Oswaldo Cruz, Rio de Janeiro, 82:43-49.

Le Minor L. \& Popoff, M.Y. 1987. Designation of Salmonella enterica sp. nov. as the type and only species of the genus Salmonella. Int. J. Syst. Bacteriol. 37:465-468.

Monteverde J.J., Simeone D.H., Morán N., Hermida C.A. \& Colombino M.M. 1969. Microbiología de alimentos. VI. Salmonelas en carne y ganglios linfáticos de equinos recién sacrificados. Revta Fac. Agron. Vet., B. Aires, 17:5760.

Palmer J.E., Benson C.E. \& Whitlock R.H. 1985. Salmonella shed by horses with colic. J. Am. Vet. Med. Assoc. 187:256-257.

Paula O., Macedo L.R.T. \& Hofer E. 1975. Pesquisa de Salmonella em eqüinos. V Congr. Bras. Microbiologia, Salvador, BA. (Resumos)

Pérez M., Vaccaro H. \& Gutierrez E. 1950. Investigación de salmonellas en ganglios mesentéricos de eqüinos. Arqs V Congr. Int. Microbiologia, Rio de Janeiro, 1:384-388.

Pether J.V.S. \& Gilbert R.J. 1971. The survivals of salmonellas on fingertips and transfer of the organisms to food. J. Hyg. 69:673-681.

Quevedo F., Dobosch D. \& González E. 1973. Contaminacion de carne equina con salmonelas: un estudio ecologico. I. Equinos portadores. Gac. Vet., B. Aires, 35:119-123.

Quevedo F., Dobosch D., Michanie S.C. \& González E.R. 1974. Contaminacion de carne equina con salmonelas: un estudio ecologico. III. Importancia del manipulador humano. Gac. Vet., B. Aires, 36:24-28.

Report of a Working Party of the Public Health Laboratory Service 1964. Salmonella in abattoirs, butchers' shops and home-produced meat, and their relation to human infection. J. Hyg. 62:283-302.

Schothorst M.V. \& Kampelmacher E.H. 1967. Salmonella in meat imported from South American countries. J. Hyg. 65:321-325.

Smith B.P., Reina-Fuerra M. \& Hardy B.S. 1978. Prevalence and epizootiology of equine salmonellosis. J. Am. Vet. Med. Assoc. 172:353-356.

Taunay A.E., Fernandes S.A., Tavechio A.T., Neves B.C., Dias A.M.G. \& Irino K. 1996. The role of public health laboratory in the problem of salmonellosis in São Paulo, Brazil. Revta Inst. Med. Trop., São Paulo, 38:119-127.

Zamora M.R.N., Lopes A.E., Moura A.M.C. \& Araújo H.L. 1978. Ocorrência de Salmonella em carne de equí́deos em matadouro de Pernambuco. Anais XVI Congr. Bras. Medicina Veterinária, Salvador, BA, p.155. 